\title{
CUERPO ANORMAL-CUERPO PROSCRITO: GENEALOGÍA CONTRA LA DIGNIDAD DEL PODER
}

\author{
ABNORMAL BODY-BANNED BODY: GENEALOGY AGAINST THE DIGNITY OF \\ POWER
}

Rodrigo Browne

Universidad de Playa Ancha, Valparaíso, Chile

\begin{abstract}
Resumen:
El problema que se cuestionará en la presente comunicación forma parte de las clasificaciones binarias que, desde Occidente, se han construido para leer, a su manera y de acuerdo a sus intenciones, los discursos de la minoría. Discursos de minorías que se vislumbran en los marginados, en los anormales, en lo que el mismo discurso de poder denominó como el sexo opuesto, en los Otros. Otros dejados de lado por diversas diferencias culturales que se traducen en idiomas, discursos sexuales e idiosincrasias fuera de lo definido canónicamente.
\end{abstract}

\section{Palabras claves:}

Sexualidad, androginia, anormales, otredad.

\section{Abstract:}

The problem questioned in this talk is part of the binary classifications which have been set up from West in order to read the speeches of the minority, its way and regarding their intentions. Minority speeches noticed in outcasts, in abnormal ones, in people who were called by the speech of power as the opposite sex, in the Other ones. Other ones who were put aside by many cultural differences which are translated into languages, sexual speeches and idiosyncrasies apart from the canon.

\section{KEY WORD:}

Sexuality, androgyny, abnormal, otherness. 
"El hombre es una invención..." Michel Foucault

“En el mes de febrero de 1868 fue encontrado en una habitación del barrio del Odeón el cadáver de Abel Barbin, que se había suicidado con un hornillo de carbón. Había dejado el manuscrito del texto que precede" M. F.

\section{"Me duele el sexo verdadero"}

Herculine Barbin llamada Alexina B. o Abel Barbin es un/una anormal. Es una enferm@ que, de acuerdo a los constructos de los poderes de la normalización, debe ser excluid@. Víctima de una práctica de desviación y rechazo que nace de su diferencia como minoría emplazada fuera de las formas habituales. En este momento y en este caso es donde se diagnostican, encuentran y confrontan los discursos de poder con los de la otredad. Herculine Barbin o Alexina B. participa de los dispositivos Otros y, por tanto, se ve afectada por las indignas diatribas del poder.

Herculine o Alexina sufre la marginación como resultado del operativo instaurado por las fuerzas que ejercen poder sobre los locos, los criminales, los desviados, los niños, los ancianos, los pobres, las mujeres, los cesantes... los Otros. Estos “anormales" -como los tildaría Michel Foucault (1975)- son objeto de descalificaciones, exilios, rechazos, privaciones, negaciones, desconocimientos, "(...) es decir, todo el arsenal de conceptos o mecanismos negativos de exclusión” (Foucault, 1975, 2001: 51).

Para dicho pensador surgen tres círculos donde se presentan los problemas de estas anomalías. El monstruo humano es quien no respeta las leyes. Leyes que no sólo se plantean desde el campo de lo jurídico, sino también en el ámbito de lo natural Violadores de la justicia y la naturaleza: "jurídico biológico". Por ello, el monstruo "es el gran modelo de todas las pequeñas diferencias" (Ibidem, 62). Herculine o Abel Barbin llamad@ Alexina B. es un monstruo humano.

En su genealogía de la anomalía, Foucault continúa refiriéndose a la figura del individuo a corregir. El individuo a corregir se encontrará merodeando las familias, las escuelas, los talleres, las calles, los barrios, las iglesias, la policía, etcétera. Por sus características es mucho más común que el monstruo humano. El individuo a corregir aparenta normalidad, a pesar de ser un anormal a escala. Parece regular dentro de su irregularidad. Es un incorregido que figura como correcto, un correcto por corregir aún más, en permanente supervisión por el sistema que lo define en los márgenes. “Lo que define al individuo a corregir, por lo tanto, es que es incorregible" (Ibidem, 64). Su incorregibilidad lo lleva a ser sometido a procesos de domesticación, a una nueva tecnología de poder: de recuperación y sobrecorrección.
El tercer anormal es el niño masturbador. Surge en el campo de la familia: en la habitación, la cama, el baño y el cuerpo, y sus supervisores son sus padres y los médicos que lo controlan.

La masturbación es el secreto universal, el secreto compartido por todo el mundo, pero nadie comunica nunca a ningún otro. Es el secreto poseído por todos, el secreto que no llega jamás a la conciencia de uno mismo y al discurso universal (...) y la fórmula general es la siguiente (...): "Casi nadie sabe que casi todo el mundo lo hace" (Foucault, 1975, 2001: 65)

Estos discursos "verdaderos" que todos conocen (y no reconocen) son base fundamental de gran parte de los problemas sociales. En síntesis, es una desviación de la naturaleza sexual. En una entrevista a Lucette Finas (La Quinzaine Littéraire, $\mathrm{n}^{\mathrm{O}}$ 247 - 1977) titulada "Las relaciones de poder penetran en los cuerpos", este pensador marca una importante diferencia entre sexo y sexualidad. Para él, dicha distinción está supeditada a una idea de poder conectada a los formatos insertos dentro de la ley y de la prohibición. Es decir, el poder construyó un mecanismo de sexualidad para negar al sexo, para negar, por ejemplo, la masturbación. Frente a esto, la sexualidad es una invención de las sociedades occidentales, olvidándose que, en los individuos, el deseo es un síntoma de creación: “El sexo no es una fatalidad, es una posibilidad de acceder a una vida creadora" (Foucault, 1982a, 1999: 417).

Estas construcciones sociales, Foucault las asocia con un orden del discurso. En su lección inaugural, denominada El orden del discurso, al ingresar al Collège de France (1970) plantea: “(...) como si el discurso, lejos de ser ese elemento transparente o neutro en el que la sexualidad se desarma y la política se pacifica fuese más bien uno de esos lugares en que se ejercen, de manera privilegiada, algunos de sus más temibles poderes" (Foucault, 1970, 1987: 12) y sobre lo mismo prosigue advirtiendo que en el discurso las prohibiciones denotan sus estrechas relaciones con el deseo y el poder. Aquí es donde recuerda el discurso de los Otros, de los enfermos, de los marginados, de los locos, de los excluidos, de los anormales: los prototipos del monstruo, el incorregido y el masturbador.

El orden del discurso confronta estas segregaciones con normativas o convenciones, es decir, con determinadas leyes que se adaptan a un orden establecido y cuyo poder lo obtiene lisa y llanamente de los propios hombres. Foucault relaciona dicho orden con un discurso verdadero que es excesivamente respetado y jerarquizado, sobre todo en la sociedad occidental que, desde hace siglos, ha tenido que buscar apoyo en lo natural, lo verosímil, en la sinceridad y en la ciencia.

Los que no respeten dichas normas del discurso quedan excluidos, marginados y se les relaciona con lo prohibitivo, la separación de la locura y la voluntad de 
verdad. Foucault destaca principalmente este último punto y llega a vincularlo con el pensamiento del Afuera. La intención es mantener sus límites fiscalizados y controlados para no contagiarse con extraños provenientes de ese afuera. Esta división permanente entre lo normal y lo anormal -nos sugiere Foucault- se aplica a otros objetos distintos que dibujan una marcación binaria cuya tarea es medir, controlar y corregir a estos anormales externos. Así lo manifiesta Claire Parnet:

Los dualismos no se basan en unidades, se basan en elecciones sucesivas: ¿eres blanco o negro, hombre o mujer, rico o pobre, etc? ¿Coges la mitad derecha o la mitad izquierda? Siempre hay una máquina binaria que preside la distribución de los papeles y que hace que todas las respuestas deban pasar por preguntas prefabricadas, puesto que las preguntas ya están calculadas de antemano en función de las posibles respuestas a tenor de las significaciones dominantes. Así es cómo se constituye un patrón tal que todo lo que no pase por él no puede materialmente ser oído (Parnet, 1977, 1997: 25).

Para ello, Foucault -a partir de algunas referencias de Maurice Blanchot- invita a pensar el afuera. Invita a una arqueología que va más allá de las minorías, que se vive y percibe en el afuera y que se dibujaría como múltiples experiencias del cuerpo, del espacio, de los límites de la voluntad, de la presencia indeleble del Otro. El discurso de autoridad es quien decide quien debe estar en el afuera.

Esta última postura se puede corroborar con Edward Said. Dicho pensador propone una particular mirada de y sobre Oriente, “(...) hasta entonces considerado un simple hecho de la naturaleza, traté de develar la invertebrada y multiforme obsesión geográfica por un mundo a menudo inaccesible que ayudó a Europa a definirse por el hecho de ser opuesto" (Said, 2002: 9-10). Amin Maalouf (1998), por su parte, desarrolla lo anterior planteándolo desde una personal mirada: “Muchas veces, la identidad que se proclama está calcada -negativo- de la del adversario" (Maalouf, 1998, 1999: 25). La identidad, para Renato Ortiz (2000), es consecuencia directa de la organización interna de las sociedades modernas. Para Said, los viajeros de siglos pasados se excusaban al indicar que conocer y acercarse a Oriente era importante para “(...) modelar vuestro carácter -es decir vuestra propia identidad-..." (Said, 1978: 235), pero, lo que efectivamente se pretendía era solidificar el antisemitismo, la xenofobia y las aprensiones raciales en general.

Marc Augé tampoco se queda atrás en este debate y asegura que la Europa occidental construye todo su sentido a partir de un afuera lejano, exótico y perdido, “(...) antes 'colonial', hoy 'subdesarrollado', que han privilegiado las antropologías británica y francesa" (Auge, 1992, 1993: 17). Sami Naïr, por su parte, ve el discurso sobre el Otro como un argumento para defenderse frente al foráneo desconocido. "Considerado imaginariamente un enemigo, el Otro hace que se olvide la universalidad del género humano" (Naïr, 1996, 1998: 130). Ante esto, nuevamente las palabras de Said requieren de atención: "Además, cada cultura define a sus enemigos, algo que existe más allá de su espacio y que la amenaza" (Said, 2000, 2004: 40)

La verdad, por lo mismo, se presenta en quienes asumen el orden del discurso eurocéntrico-occidental como una riqueza, como fecundidad, como una fuerza universal, ejemplifica Foucault y explica que se ignora, por el contrario, la voluntad de verdad, como portentosa maquinaria designada a relegar. Esta exigencia clásica que Derrida ha propuesto llamar significado transcendental no remite, ni se relaciona con ningún significante, “(...) excedería la cadena de los signos, y él mismo no funcionaría, llegado el momento, como significante" (Derrida, 1968, 1977: 28)

Para Foucault es necesario criticar al orden del discurso y para ello recurre a la idea de comentario. El comentario es el desfase entre el primer y el segundo texto; ambos y viceversa, representan cometidos solidarios. La importancia de este juego es la construcción de nuevos y plurales discursos. Discursos en forma indefinida:

El cabrilleo indefinido de los comentarios es activado desde el interior por el sueño de una repetición enmascarada (...) conjura el azar del discurso al tenerlo en cuenta: permite decir otra cosa aparte del texto mismo, pero con la condición de que sea ese mismo texto el que se diga (...) La multiplicidad abierta y el azar son transferidos, por el principio del comentario, de aquello que podría ser dicho, sobre el número, la forma, la máscara, la circunstancia de la repetición. Lo nuevo no está en lo que se dice, sino en el acontecimiento de su retorno (Foucault, 1970, 1999: 29).

El comentario limita, enmascara o vela el azar del discurso por medio del juego de una identidad que tiene la forma de la repetición y de lo mismo y que encuentra, en el momento, la disciplina que es como un principio de dominio de la producción del discurso. Foucault define sus límites por el ejercicio de una identidad que tiene la capacidad de reactualizar permanentemente las normas y amplía este concepto a sociedades de discurso, indicando que éstas tienen como cometido conservar y producir discursos que se distribuyen, según reglas y códigos estrictos y sin que los detentadores sean desposeídos de la función de distribución que, acto seguido, les permite desplegar formas de apropiación del secreto y de la no intercambiabilidad.

En síntesis, todo funciona como prohibiciones, barreras, umbrales, límites. Disposiciones determinadas para frenar las proliferaciones del discurso, logrando, con esto, que se alivianen los sectores más peligrosos y organice el desorden que por sí mismos conlleva, “(...) y que su desorden se organice según figuras que esquivan lo más incontrolable; todo pasa como si hubiese querido borrar hasta las marcas de su irrupción en los juegos del pensamiento y de la lengua" (Foucault, 1970, 1999: 50). 
En estas sociedades de discurso hay una acentuada logofobia que estimula un fuerte temor hacia los acontecimientos, contra las cosas dichas, contra los enunciados, contra todo lo que allí puede haber de desordenado, peligroso, violento, discontinuo, contra ese enorme murmullo perpetuo y desordenado del discurso. Por ello, los discursos deben ser asimilados como experiencias discontinuas en permanente cruce y yuxtaposición e incluso, en ocasiones, ignorándose y/o excluyéndose.

Para Giulia Colaizzi (1990), los cimientos que soportan el orden del discurso son producto específico de vínculos de poder que tienden a marcar al sujeto para historizarlo $\mathrm{y}$, por lo mismo, es necesario crear un planteamiento crítico sobre estas definiciones sociales y culturales. Aboga, en síntesis, por un discurso crítico-contracultural que cuestione y polemice la ordenación delimitada por Occidente del mismo discurso.

Por ello el "objeto de estudio", así como el "sujeto" del discurso, están desprovistos de cualquier cualidad que pudiese ser considerada como "esencial", ontológica o trans-histórica, y son mostrados en tanto construcciones, como específicos productos temporales de las relaciones de poder entre superficies, cuerpos e instituciones (Colaizzi, 1990: 14).

Esta marca sexual, según Colaizzi, es comprendida en el contexto de la razón científica del Hombre. Idea surgida a la luz del cogito cartesiano y que se ha transformado en pilar decisivo de las lecturas segregadoras. Esta postura actúa como un conjunto de discursos que tienen el propósito de universalizar al hombre: como fundamento de todas las positividades y como centro de todo accionar empírico.

Sin embargo Foucault -que analiza (y reanima) desde otro punto de vista esta cuestión- indica que el hombre no debe darse en la claridad inminente y soberana del cogito. El hombre, por tanto, funda una dimensión ilimitada, abierta que se estimula desde una parte de sí mismo que no, necesariamente, se detiene en un cogito al momento de pensar y que, por el contrario, “(...) va de esta pura aprehensión a la obstrucción empírica, al amontonamiento desordenado de los contenidos, el desplome de las experiencias que escapan a ellas mismas, a todo el horizonte silencioso de lo que se da en la extensión arenosa de lo no pensado" (Foucault, 1966, 1986: 314).

El hombre es parte del desconocimiento. Falta de conocimiento que invita al pensamiento a ser sobrepasado por su propio ser y que le permite, a su vez, rememorar a partir del olvido. Con esto, la forma moderna de reflexión, la reflexión trascendental no tiene cabida. La idea, bajo esta posición, no es detenerse en juicios necesarios, sino preguntarse ¿cómo hacer que el hombre piense lo que no piensa? Como el hombre puede aproximarse a aquello que desconoce, que se le arranca y que se le presenta como una externalidad intransigente.
A partir de este desplazamiento de la cuestión trascendental, el pensamiento contemporáneo no pudo evitar el reanimar el tema del cogito. ¿Acaso Descartes no descubrió la imposibilidad de que no fueran pensadas a partir del error, de la ilusión, del sueño y de la locura, de todas las experiencias del pensamiento no fundadas -tanto que el pensamiento de lo mal pensado, de lo no verdadero, de lo quimérico, de lo puramente imaginario aparecían como lugar de posibilidad de todas estas experiencias y primera evidencia irrecusable? (Foucault, 1966, 1986: 315).

Entonces, existe una diferencia entre el cogito moderno y el planteado por Descartes. La propuesta de Descartes pretendía sacar a flote el pensamiento de una manera más general en relación a todos los pensamientos que son el error o la ilusión, logrando, con esto, anular su peligro y proponiendo un método para su prevención. En cambio, el cogito moderno busca mantener la distancia que separa y une el pensamiento presente con aquello que pertenece al pensamiento, con aquello ligado a lo no-pensado, "(...) recorrer, duplicar y reactivar en una forma explícita la articulación del pensamiento sobre aquello que (...) no es pensado" (Ibidem) y que no le es extraño, ni ajeno. Desde este punto de vista, el cogito no es un lúcido descubrimiento que sentencia que todo pensamiento es pensado, sino que ensalza la interrogación de cómo el pensamiento se piensa en el afuera, “(...) fuera de aquí y, sin embargo, muy cerca de sí mismo, cómo puede ser bajo las especies de lo no-pensante" (Ibidem). Esta es la advertencia de algo que se aleja de lo cartesiano y del propio análisis kantiano ya que pretende preguntarse sobre el ser del hombre en esta nueva dimensión desconocida y en la cual el pensamiento se despiensa, impiensa y se articula en ello. La idea es indagar en las posibilidades que tiene el propio pensamiento de escaparse de si mismo y de dirigirse a nuevas interrogaciones, múltiples y diseminadas del ser.

Este no-pensamiento, por tanto, no se destina a la lógica del "soy". No se reduce a la afirmación de un ser, sino que se abre a una amplia serie de cuestionamientos en las que sí se pregunta por el ser. Lo impensado no está instalado y positivizado en el hombre, sino está en relación con el Otro, a pesar de que ha sido un condimento impávido y permanente del Hombre del siglo XIX. Hombre moderno que al surgir en la episteme entraña un precepto que afecta al interior del pensamiento, sin interesarle que esté acuñado por los imperativos de una moral ${ }^{1}$, de una política, de un humanismo, de una definición de lo occidental e incluso de un interesado orden del discurso oriental. Con esto, en consecuencia, se invierte la ecuación cartesiana y el hombre, como tal, se preocupa más por el existir que por el pensar y no así por "el pienso, luego existo". "Dejemos hablar a aquellos que incitan al pensamiento a salir de su retiro y a hacer su

1 "A decir verdad, el pensamiento moderno no ha podido nunca proponer una moral: pero la razón de ello no es que sea pura especulación; todo lo contrario, es desde su inicio y en su propio espesor un cierto modo de acción" (Foucault, 1966, 1986: 319). 
elección; dejemos obrar a los que quieren, más allá de toda promesa y en la ausencia de virtud, constituir una moral" (Ibidem).

Para Foucault, este orden del discurso es un orden del saber, y genealogiza la cuestión del Hombre como ciencia precisando que las ciencias humanas surgieron bajo la consigna de algún racionalismo presionante, de cierto tipo de problema científico no solucionado o a partir de un interés práctico: “(...) el día en que el hombre se constituyó en la cultura occidental a la vez como aquello que hay que pensar y aquello que hay que saber" (Foucault, 1966, 1997: 334). Gilles Deleuze, sobre lo mismo, anuncia la necesidad de replantear la hermética y confinada figura del Hombre: "Y, si el hombre ha sido un modo de aprisionar la vida, ¿no ha de liberarse necesariamente en otra forma la vida en el hombre mismo?" (Deleuze, 1985, 2002: 147).

\section{EL NO-PENSAMIENTO Y LA NO-IDENTIDAD DE BARBIN}

El suicidio de Alexina B., producto de su negación a transformarse en el hombre que hay en ella, es consecuencia de los discursos de poder de las ciencias humanas. Las muchas Herculine o Alexina necesitaban liberarse de las normas de los discursos de poder y no caer en la exigencia de asumirse como un sexo verdadero, como Abel Barbin.

Discursos de indignidad que apelan y construyen sus "verdades" desde los discursos de las minorías -o si se radicaliza aún más la situación- desde el pensamiento del afuera. Estos preceptos son discursos que "(...) pueden matar, discursos de verdad y discursos -ustedes son la prueba y los testigos- que dan risa" (Foucault, 1975, 2000: 19).

Los hermafroditas, por ejemplo, son víctimas de estas marginaciones provenientes de los "verdaderos" discursos de autoridad que matan y dan risa. Los hermafroditas son un tercer tipo de monstruosidad. Son los nuevos monstruos que despiertan en la transición del siglo XVIII al XIX. En el siglo XVI, los hermafroditas eran ejecutados, quemados y sus restos eran despedidos a los vientos. “También a comienzos del mismo siglo encontramos a otros dos hermafroditas a quienes quemaron vivos y sus cenizas fueron arrojadas al viento, simplemente porque vivían juntos $\mathrm{y}$, entonces, necesariamente (...) cada uno de ellos empleaba sus dos sexos con el otro" (Foucault, 1975, 2000: 74)

Herculine o Alexina era hermafrodita. Así lo cuenta en su experiencia biográfica relatada por el(la) mism@, rescatada del anonimato y publicada por Foucault en 1978. Alexina/Abel se enfrenta a los discursos de autoridad. Alexina/Abel no quiere someterse a los dictámenes de los médicos y los sacerdotes que debían erradicar las amenazas de la anormalidad, del hermafroditismo y del homosexualismo. La naturaleza tildada como anormal es necesario marchitarla.

En su introducción a la biografía de Alexina Barbin, Foucault se cuestiona sobre la verdad del sexo, sobre la existencia de un sexo verdadero y asegura que la tozudez de las sociedades occidentales modernas y eurocéntricas responde afirmativamente a esta consulta. “Han hecho jugar obstinadamente esta cuestión del 'sexo verdadero' en un orden de cosas donde sólo cabe imaginar la realidad de los cuerpos y la intensidad de los placeres" (Foucault, 1978, 1985: 11). El cuestionamiento de Foucault es preciso al desmenuzar esa imperativa exigencia que, frente a la dualidad hermafrodita, obliga a poseer un solo sexo: el sexo verdadero.

Antes de la consolidación de las ciencias humanas -que por lo demás no sólo dejan fuera a los homosexuales y a los hermafroditas, sino también alejan la figura de la mujer (Colaizzi, 1990)- existía la opción de tener ambos sexos en un cuerpo².

Las teorías biológicas sobre la sexualidad, las concepciones jurídicas sobre el individuo, las formas de control administrativo en los Estados modernos han conducido paulatinamente a rechazar la idea de una mezcla de los dos sexos en un solo cuerpo y a restringir, en consecuencia, la libre elección de los sujetos dudosos. En adelante, a cada uno un sexo y uno solo. A cada uno su identidad sexual primera, profunda, determinada y determinante; los elementos del otro sexo que puedan aparecer tienen que ser accidentales, superficiales o, incluso, simplemente ilusorios. Desde el punto de vista médico, esto significa que, ante un hermafrodita, no se tratará ya de reconocer la presencia de dos sexos yuxtapuestos o entremezclados, ni de saber cuál de los dos prevalece sobre el otro, sino de descifrar cuál es el sexo verdadero que se esconde bajo apariencias confusas (Foucault, 1978, 1985: 12-13).

Herculine Barbin, bautizada inicialmente como Alexina, fue educada en el seno de una familia de bajos recursos y en un ambiente radicalmente femenino y religioso. A una edad adulta fue -después de un cambio de sexo legal a través de procedimientos judiciales y de estado civil- redefinida y obligada a funcionar como hombre.

\footnotetext{
2 "En este caso, correspondía al padre o al padrino (...) determinar, en el momento del bautismo, el sexo que iba a mantenerse (...) Pero más tarde, en el umbral de la edad adulta, cuando se aproxim el momento de casarse, el hermafrodita era libre de decidir por sí mismo si quería continuar siendo del sexo que se le había atribuido o si prefería otro. La única condición impuesta era la de no cambiar nunca más, y mantener hasta el fin de sus días lo que entonces había declarado, bajo pena de sodomía" (Foucault, 1978, 1985: 12). A pesar de lo anterior, en los periodos del platonismo era rechazada la posibilidad de poseer ambos sexos. Aristófanes en "El Banquete" precisa: "La naturaleza humana era antes muy diferente de como es hoy en día. Al principio hubo tres clases de hombres: los dos sexos que subsisten hoy día y un tercero compuesto de estos dos y que ha sido destruido y del cual sólo queda nombre. Este animal formaba una especie particular que se llamaba andrógina porque reunía al sexo masculino y al femenino, pero ya no existe y su nombre es un oprobio" (Aristófanes en Platón, 1986, 139-140).
}

Revista Internacional de Culturas y Literaturas, abril 2006 
Por decisión del tribunal civil de Saint Jean d'Angély de fecha 21 de junio de 1860, ha sido ordenado que la presente sea rectificada en los términos siguientes:

1) que el niño que allí figura será designado como siendo del sexo masculino.

2) y que el nombre de Abel sustituirá a los de Adelaide Herculine. Saint Jean d'Angély, el 22 de junio de 1860.

Pero, desafortunadamente para las normas de turno, Alexina nunca se adaptó a su nueva condición y la impotencia ante este cambio la llevó a suicidarse. Atentó contra su vida porque se sentía afectada por una identidad que no le correspondía, por una negación de su propia identidad, por una no identidad. La modificación sexual para Alexina fue un acto de biopoder (cuerpo-poder) que atacó la parte más íntima de su ser, anulándola en su explícita corporeidad. El cuerpo de Alexina pasa de un cuerpo voluntario-libre a un cuerpo proscrito por las reglas que fundan las ciencias humanas. "Profundamente hastiado de todo y de todos, soporto, sin conmoverme, las injusticias de los hombres, sus odios hipócritas. No podrían alcanzarme en el seguro refugio donde me escondo" (Herculine Barbin o “Alexina B.”, 1868, 1985: 114).

Las preocupaciones -no sólo en el ámbito sexual, sino también cultural- que surgen a la hora de delimitar las identidades y sus posibles disquisiciones son temas centrales en la obra de Said. "Ignorar esta agitación en el seno de cada cultura y pensar que existe una homogeneidad total entre cultura e identidad equivale a desconocer lo que es vital y fecundo" (Said, 2000, 2004: 40). La identidad, en ocasiones, es construida desde la diferencia, como un discurso de poder de una cultura dominante, oficial o canónica. Sin embargo, existen culturas disidentes, heterodoxas y que descansan en tendencias antiautoritarias y en oposición a la cultura del discurso de autoridad. "Este conjunto de prácticas asociadas a diferentes outsiders -pobres, inmigrantes, bohemios, rebeldes y artistas- puede llamarse contracultura..." (Ibidem). De ésta se desprende un discurso crítico que se contrapone a la autoridad y la cuestiona. Lo intercultural se percibe en la convivencia entre las afirmaciones cuestionadas y las contra-afirmaciones: en este conflicto se vislumbra el sentido crítico, el debate y la creación ENTRE.

Colaizzi manifiesta que la verdad del orden de las cosas debe ser replanteada a partir de preguntas inéditas. Cambiar la forma de consultar implica un gesto y un giro revolucionario. Los nuevos cuestionamientos en el ámbito de la recuperación de una "amujer" llevaron a alejarse de las definiciones identitarias dogmáticas y restituir la sexualidad y el cuerpo femenino a partir de novedosos universales: "Pensaron el cuerpo como metáfora; no el lugar homogéneo de la alteridad sino un espacio históricamente determinado y atravesado por una multiplicidad de prácticas discursivas" (Colaizzi, 1990: 25).
Los dispositivos Otros son habituales en diferentes áreas sociales que, en ocasiones, se escapan de las mismas nociones que propone Foucault, con el ejemplo de los hermafroditas y la sexualidad en general, y Said, en el campo de los estudios de la cultura. Al indagar en los medios de comunicación y en un ejercicio crítico de la prensa, se pueden advertir algunas analogías a lo antes mencionado.

Como excepción a la norma establecida, y en el campo inmediato de lo empírico, parece oportuno recuperar el reportaje publicado en La Nación Domingo de Santiago de Chile que recoge una propuesta diferente en relación con la "sexualidad verdadera" de un sector de los habitantes de dicho país. Bajo el título "Chicas que desean a chicas" se analiza la bisexualidad femenina, trasgrediendo las censuras implícitas en y de una sociedad enmascaradamente conservadora. "La sociedad rechina sus dientes, las abuelas se escandalizan y los mecanismos de censura se activan. ¡Dios nos pille confesados!" (López de Santamaría, 2004: 42). El objetivo de esta opción no pretende caer en el juego del homosexualismo, sino sentir el placer sexual en su plenitud, agotando las alternativas y desafiando las fronteras impuestas por los discursos de autoridad.

Loreto asume su bisexualidad como algo completamente normal. Postula que no pretende convertirse en lesbiana porque cerrar la posibilidad a estar con hombres tampoco es su idea. No descarta casarse, formar una familia y ser mamá, pero plantea que la bisexualidad va a ser algo con lo que siempre va a vivir (López de Santamaría, 2004: 43).

Como se desprende del estudio de Colaizzi sobre feminismo y teoría del discurso, estas acciones simpatizan con las tendencias que buscan respuestas, a modo de estrategias de contrapoder, a la ausencia que la mujer ha tenido como sujeto histórico en la arquitectura de Occidente. Basada en los trabajos de Teresa de Lauretis, precisa que “(...) la forma en que el psicoanálisis, al establecer el 'falo' como el significante único y universal del poder, ha hecho de la mujer un mero dispositivo portador de 'Carencia' metafísica, colocándola fuera de lo social y de lo cultural" (Colaizzi, 1990: 16). Por tanto, la mujer se localiza sólo por su carácter biológico-natural-sexual y se margina de los estadios de relevancia a nivel de relaciones de poder y del discurso: mujer ausente como sujeto teórico y mujer prisionera como sujeto histórico. El pensamiento occidental instaura a la mujer en un modelo basado en la cuestión de una naturaleza menor y una primacía biológica del Hombre.

Por lo mismo, Foucault enfatiza que el psicoanálisis de Freud y sus conclusiones sobre la mujer, los estudios de Hegel y los postulados de Marx hicieron vista gorda a esta lectura occidental de la verdad y, en cambio, Sade, Nietzsche, Artaud y Bataille, entre otros, la han puesto en el tapete, superando a todos aquellos que la ignoraron y la ignoran. “Su necedad es creer que todo pensamiento 'expresa' la ideología de una 
clase: su involuntaria profundidad es mostrar con el dedo el moderno modo de ser de pensamiento" (Foucault, 1966, 1986: 319).

\section{EL PODER EN LOS CUERPO}

Estos múltiples discursos se confrontaron a las proyecciones del canon, tal cual como lo enfatiza Foucault al preocuparse sobre el poder y su implicación en los cuerpos: Cuerpo-poder, biopoder y sus afectos y efectos en virtud de los dictámenes de autoridad. Las emergencias en las tecnologías del poder -de la normalización en discusión con la anormalización- no son, solamente, un efecto de armonía entre el saber médico y el poder judicial, sino que la sociedad moderna planteó ciertos tipos de poder que colonizaron y reprimieron al propio saber médico y al propio poder judicial: “(...) un tipo de poder que finalmente desemboca en el escenario teatral del tribunal, apoyado, desde luego, en la institución judicial y la institución médica pero, en sí mismo, tiene su autonomía y sus reglas" (Foucault, 1975, 2001:38). Con esta hábil metodología, el discurso de poder hizo soberanía en nuestras sociedades.

En La voluntad de saber (1976a), primer tomo de la Historia de la sexualidad, dicho pensador advierte que Occidente fue colaborador, desde la edad clásica, de oscuras modificaciones en los modelos de poder. Es así como el cuerpo, como cuerpopoder se asimiló a una máquina, “(...) su educación, el aumento de sus aptitudes, el arrancamiento de sus fuerzas, el crecimiento paralelo de su utilidad y su docilidad su agilidad, su integración en sistemas de control eficaces y económicos..." (Foucault, 1982, 1994: 168): anatomopolítica del cuerpo humano.

Posteriormente, se optó por el cuerpo-especie, el cuerpo consumido por el aparato de los sistemas vivientes que sustentan a la biología, supervisando la reproducción, la salud, la duración de la vida y la senectud: biopolítica de la población. Con estas determinaciones se define el poder sobre la vida. Es la disciplina corporal y la estabilización de los afueras y sus marginalidades.

Esto es lo que denomina Foucault como la era del biopoder: por una parte las disciplinas (escuelas, colegios, cuarteles, talleres) que estudiaban el aprendizaje, la educación, el orden del discurso y, por otra, las regulaciones de población: problemas de demografía, longevidad, salubridad pública, migración, es decir, el valor de las relaciones entre recursos y habitantes, así como también el estudio del surgimiento explosivo de diferentes y variadas técnicas para contener a los cuerpos y vigilar a los pobladores. Como se evidenció en párrafos anteriores, el dispositivo de la sexualidad es uno de los ejes esenciales de opresión disciplinaria. 1984 (1949) es sólo un ejemplo:

Llevaba un "mono" ceñido por una estrecha faja roja que le daba varias veces la vuelta a la cintura realzando así la atractiva forma de sus caderas; y ese cinturón era el emblema de la Liga juvenil Anti-Sex (...) Sin embargo se dio cuenta mejor que antes de por qué la odiaba. La odiaba porque era joven y bonita y asexuada; porque quería irse a la cama con ella y no lo haría nunca; porque alrededor de su dulce y cimbreante cintura, que parecía pedir que la rodearan con el brazo, no había más que la odiosa banda roja, agresivo símbolo de castidad (Orwell, 1949, 1984: 18 y 23-24).

Biología del poder o biopoder que fue un argumento fundamental e imprescindible para el crecimiento del capitalismo: “(...) éste no pudo afirmarse sino al precio de la inserción controlada de los cuerpos en el aparato de producción y mediante un ajuste de los fenómenos de población a los procesos económicos" (Foucault, 1976, 1984: 170). Pero este modelo necesitó esclavizar aún más a sus discípulos. Además de fortalecer la docilidad y difusión de dicho modelo, procuró, indirecta e inconscientemente para quienes la padecían, fórmulas de poder que incrementarían los dominios, las condiciones y las condicionantes de la vida en general.

Desde este punto de partida, surge una explosión de tecnologías políticas que comienzan a violentar cuerpo, salud, condiciones de vida y espacios de existencia. Se insinúa, entonces, una sociedad normalizadora como producto de una tecnología de poder enfocada en el cuerpo.

$\mathrm{Al}$ igual que el desarrollo y crecimiento de las instituciones, este sistema protegió la estabilidad de las relaciones de producción, las estrategias biopolíticas -puestas en marcha en el siglo XVIII como técnicas de poder aplicadas a todos los estadios de cuerpo social a través de instituciones disciplinarias- se desenvolvieron en el ámbito de las propuestas económicas.

Las técnicas de poder se han concebido para responder a las exigencias de producción. Éstas se tornan en agentes de separación y jerarquización social, definiendo a unos de otros y avalando relaciones de dominación y decisiones hegemónicas, es decir, marcando diferencias. El control hombre-capital, el engranaje entre aumento de los grupos humanos y extensión de fuerzas productivas, la distribución diferida de la riqueza fueron resultado, en gran medida, de la implantación, en sus múltiples formas y signos, de estas técnicas. Hombre-capital que se torna en una especie viviente posible de moldear y manipular y fácil de acomodar en un territorio determinado. Uno de los primeros indicios donde lo biológico se refleja en lo político. Es un síntoma del sedentarismo de las sociedades controladoras: cuerpo proscrito, cuerpo dominado, cuerpo marginado: “(...) haber tomado a su cargo a la vida, más que la amenaza de asesinato, dio al poder su acceso al cuerpo" (Foucault, 1976, 1984: 173).

El poder se apodera del Hombre de las ciencias humanas. Son las reglas del juego que él mismo (como Mismo) definió, identificó y confrontó con el otro (como Otro) construido por el discurso de autoridad. Consecuencia de esto, la indignidad del 
poder (que produce indignación) simplificó, más aún a las diversas diferencias que, a la larga, se tornaron en los grandes ausentes, en los injustos marginados producto de un modelo que se levantó a la vera del Hombre de Occidente (ciencias humanas), de sus terminales corporales y su incierta fuerza indestructible. Ya que el hombre es "(...) sólo una invención reciente, una figura que no tiene ni dos siglos, un simple pliegue en nuestro saber y que desaparecerá en cuanto éste encuentre una forma nueva" (Foucault, 1966, 1997: 9 y ss.).

Confiado en este nuevo cambio de episteme, en esta revolución de lo establecido, en este acto contracultural, Foucault -ensalzado por las nociones de Nietzsche- proclama la fragilidad del Hombre, la necesaria muerte del hombre, de este Hombre (con mayúscula) eurocéntrico, moderno y patriarcal:

De hecho, entre todas las mutaciones que han afectado al saber de las cosas y de su orden, el saber de las identidades, las diferencias, los caracteres, los equivalentes, las palabras -en breve, en medio de todos los episodios de esta profunda historia de lo Mismo- una sola, la que se inició hace un siglo y medio y que quizá está en vías de cerrarse, dejó aparecer la figura del hombre (...) El hombre es una invención cuya fecha reciente muestra con toda facilidad la arqueología de nuestro pensamiento. $Y$ quizá también su próximo fin (Foucault, 1966, 1997: 375).

\section{REFERENCIAS BIBLIOGRÁFICAS}

Augé, M., Los "no lugares": espacios del anonimato: una antropología de la sobremodernidad, Barcelona, Gedisa, 1993.

Colaizzi, G., Feminismo y teoría del discurso, Madrid, Cátedra, 1990.

Deleuze, G., "El intelectual y la política. Sobre Foucault y la prisión", entrevista de Paul Rabinow y Kheit Gandal, Archipiélago, 53 (2002), Barcelona.

Derrida, J., De la Gramatología, Buenos Aires, Siglo XXI, 1971.

Foucault, M., "Las relaciones de poder penetran en los cuerpos", Microfisica del poder, entrevista de Lucette Finas, Madrid, La piqueta, 1979

----,Microfisica del poder, Madrid, La piqueta, 1979.

----, “Poder-cuerpo", Microfisica del poder, Madrid, La piqueta, 1979.

---, Herculine Barbin llamada Alexina B. Madrid, Revolución, 1985.

----Las palabras y las cosas, México, Siglo XXI, 1986.

----, El pensamiento del afuera, Valencia, Pre-textos. 1989.

----, Tecnologías del yo, Barcelona, Paidós, 1990.

----, La historia de la sexualidad 1. La voluntad de saber, Madrid, Siglo XXI, 1992.

----, Vigilar y castigar. Madrid, Siglo XXI, 1994.
,---- El orden del discurso, Barcelona, Tusquets, 1999.

----, Los anormales, Buenos Aires, Fondo de Cultura Económica, 2000.

----, “A propósito del encierro carcelario”, Un diálogo sobre el poder y otras conversaciones, Barcelona, Alianza, 2001.

----, "No al sexo rey", entrevista con Bernard Henry-Levy, Un diálogo sobre el poder y otras conversaciones, Barcelona, Alianza, 2001.

López De Santamaría, A., “Chicas que desean chicas”, La Nación Domingo (2004), Santiago de Chile.

Nair, S., "El otro como enemigo", Inmigrantes: El desplazamiento del mundo, Madrid, Instituto de Migraciones y Servicios Sociales, Ministerio de Trabajo y Asuntos Sociales, 1998.

Orwell, G., 1984. Barcelona, Destino, 1984.

Parnet, C., “Segunda parte. Una entrevista, ¿qué es?, ¿para qué sirve?”, Diálogos, Valencia, Pre-textos, 1997 Platón, "El banquete", Diálogos, Madrid, Espasa Calpe, Austral, 1998.

Said, E.W., Orientalismo, Madrid, Libertarias, 1990.

-----, "Conflictos de definiciones", Le Monde Diplomatique, Buenos Aires, 2004.

-.---, "Entre dos mundos", Fractal (2002), México, http://www.fractal.com.mx/F9said.html 